Original Research Paper

\title{
Long-Term Changes in Mangrove Landscape of the Niger River Delta, Nigeria
}

\author{
${ }^{1,2}$ Ping Wang, ${ }^{1,3}$ Aroloye O. Numbere and ${ }^{1}$ Gerardo R. Camilo \\ ${ }^{1}$ Department of Biology, Saint Louis University, St. Louis, MO 63103, U.S.A \\ ${ }^{2}$ Editorial Board of Safety and Environment Engineering, China University of Geosciences, Wuhan, China \\ ${ }^{3}$ Department of Animal and Environmental Biology, University of Port Harcourt, Nigeria
}

\author{
Article history \\ Received: 08-01-2016 \\ Revised: 23-02-2016 \\ Accepted: 17-06-2016 \\ Corresponsding Author: \\ Aroloye O. Numbere \\ Department of Biology, Saint \\ Louis University, St. Louis, \\ MO 63103, U.S.A and \\ Department of Animal and \\ Environmental Biology, \\ University of Port Harcourt, \\ Nigeria \\ Email: aroloyen@yahoo.com
}

\begin{abstract}
The Niger Delta mangrove is the third largest in the world and the largest in Africa. Since the 1960s oil and gas exploration has become an important economic activity, resulting in significant alteration of the landscape via pollution, urbanization and invasion. Landsat images of six different years $(1984,1986,2000,2003,2005$ and 2007) were used to determine land cover across $3,700 \mathrm{~km}^{2}$. Landscape was segregated between areas with oil and gas exploration and those without. Two forest types were identified namely mangrove and mixed, which were further decomposed into high (Mang 1) and low (Mang 2) density mangroves and palms. A total of 145 landscape square samples, each $6.76 \mathrm{~km}^{2}$ were randomly selected in each map and statistically analyzed and modeled. The results showed that the kappa coefficient for the six years were all $>0.9$, (i.e., 0.93, 0.07, 0.94, 0.93, 0.90 and 0.94) indicating high classification accuracy. Also great change in mangrove landscape occurred in the last decade. Locations with increased oil and gas activities had significantly decreased amount of mangrove and palm forests. Also mixed forests increased over time and had a significant negative relationship with mangrove, Mang 1 and Mang 2. Even though the total area of mangrove forest did not change significantly ( $p>0.05$ ), the total biomass of mangrove decreased $(p<0.01)$. Nypa palm abundances increased over time, yet, it is negatively affected by the exploration. Increase in mixed forest and urban region has negatively affected the mangrove forest in the Niger's delta landscape. High density mangrove forest withstood better the impacts of oil and gas exploration compared to mixed forest, but low density mangrove forest was the opposite. This suggests complex landscape level effects among different forest types.
\end{abstract}

Keywords: Mangrove, Invasive Species, Nypa Palm, Hydrocarbon Pollution, Niger Delta, Nigeria

\section{Introduction}

The Niger delta mangrove ecosystem is the third largest mangrove in the world, comprising some 36,000 $\mathrm{km}^{2}$ in area (Nwilo, 2004). It is among the 14 biomes recognized by the World Wild Life Fund for conservation (Olsen and Dinerstein, 2002). A large number of plant and animal species are found in this area (NDES, 1997). Also, a large human population lives and depends on over 70 usages of mangroves identified in the Niger Delta (NDES, 1997; Polidoro et al., 2010).
In the 1960's oil and gas exploration in the Niger delta became an important economic source. Expansion of the oil and gas industry in the last twenty years has increased dramatically, along with accompanying human activities. This, in turn, results in other negative environmental impacts like dredging of wetlands, road and channel constructions, deforestation, increased soil and water pollution. In the Niger Delta, James et al. (2007) reported that $210 \mathrm{~km}^{2}$ of mangroves forest had been removed as a result of oil and gas exploration. Beside pollution, Nypa palm (Nypa fruticans, Wurmb) 
invasion is a major threat to mangrove in the Niger Delta (CEDA, 1997). The occurrence of mangroves at the tip of the sea predisposes them to the impact of sea-level rise caused by climate change (Hewitt, 2004; Gilman et al., 2006). They are also subjected to other natural and anthropogenic disturbances and take a long time to recover (Burns et al., 1994).

Mangroves that are not fragmented by disturbances, occupy vast areas that are best studied at landscape-level rather than at a small-scale level (Turner et al., 2001). A good example of studying landscape is the use of Landsat remote sensing (Colwell, 1997) in mapping and producing images of the study area. Some studies have used Landsat to calibrate spatio-temporal disturbancemediated changes in mangroves (Anwar and Takewaka, 2014; James et al., 2007) at different spatial scales. In the Niger Delta, the impact of hydrocarbon pollution on mangroves has been done at both small (Snowden and Ekweozor, 1987; Osuji et al., 2004) and large (James et al., 2007) scale levels. We used spatial statistics to quantitatively determine the relationship between oil and gas exploration and mangrove and between mangrove and nypa palm. Nypa palm was first introduced into the Niger Delta in 1906 to fight coastal erosion, but became invasive and threatened the stability of the mangrove forest (CEDA, 1997; Keay et al., 1964). Rapid advancement of the nypa palm into the coastal terrain was facilitated by human alterations of the ecosystem. People living in coastal areas often clear large sections of the mangroves to build houses, which lead to sediment loss with negative impact on mangroves (Hayden and Granek, 2015; Stokes and Harris, 2015). These inhabitants deposit waste into the mangrove swamp (Okoye et al., 1991), which accumulates and changes the swampy soil thus making it more conducive for the growth of invasive nypa palms. The shallow root system of the palms impact sediment distribution, biodiversity and navigation along the waterways (Udofia and Udo, 2005).

This work documents the spatial pattern of change in mangrove landscape and analyzes the impact of exploration, invasion and urbanization on the mangrove ecosystem. It specifically addresses (1) how the overall landscape and mangrove forests, have changed over time, (2) how the oil and gas exploration's spatial distribution have affected mangrove change, (3) how the invasive nypa palm affects mangrove spatial patterning and (4) how oil and gas exploration's activities affect the invasion process.

The significance of this study is that it describes the trajectory of mangrove landscape changes and its replacement by nypa palms and urban regions within a twenty-year period (1984 to 2007). The study identifies nypa palm as a species that invades pure and mixed mangrove stands.

\section{Materials and Methods}

\section{Study Area}

The Niger River delta region of Nigeria covers $20,000 \mathrm{~km}^{2}$ within $70,000 \mathrm{~km}^{2}$ of wetlands, formed primarily by sediment deposition (NDES, 1997). Its mangrove forest is estimated to cover 5,000 to $8,500 \mathrm{~km}^{2}$ (Nwilo and Badejo, 2005). The climate of the zone is that of tropical monsoon with rainfall occurring almost all through the year. The mean monthly temperature is between 26 to $30^{\circ} \mathrm{C}$. The soil is swampy and grades from red to brown and the soil $\mathrm{pH}$ is between 5.8 and 7.0, which compare favorably with the values (5.5-7.2) reported by Dublin-Green (1993).

The study area is located near the city of Port Harcourt (Fig. 1) and covers an area of $3,700 \mathrm{~km}^{2}$. Two zones designated for the study are the western and the eastern zones. The western area (i.e., Buguma Town) was assigned the low impact zone because it has fewer industries and lower incidences of oil spillages, while the eastern area (i.e., Okrika Town) was assigned the high impact area because it has a refinery and a lot of oil servicing firms with high cases of oil spillages (Snowden and Ekweozor, 1987).

The commonly found species of mangroves are the red (Rhizhophora spp., Linn), white (Avicennia germinans, Linn) and black (Laguncularia racemosa, Gaertn) mangroves. But the most dominant species are the red mangroves (Ukpong, 1997) and occur in either single or mixed species stands. Nypa palm (Nypa fruticans, Wurmb) is the next dominant plant and an invasive species (CEDA, 1997).

\section{Images Pre-Processing}

We collected two satellite remote sensing data, including two Landsat-5 Thematic Mapper (TM) and four Landsat-7 Enhanced Thematic Mapper Plus (ETM+) images, spanning from 1984 to 2007 from USGS Landsat data Archive. We collected data for December and January because they are dry season and mostly cloud free (Table 1). The lower case images were radiometrically calibrated and then corrected for atmospheric effects using ENVI ${ }^{\circledR}$ image processing and analysis software, from ITT Visual Information Solutions. We used dark object subtract method for eliminating atmospheric perturbations ( $\mathrm{Lu}$ et al., 2002). This is because there is a systematic scanning gap on the ETM+ sensor images due to a Scan Line Corrector (SLC) failure, which occurred on May 31, 2003. Gap filling was thus, performed before the radiometric calibrations were done, followed by an image-to-image co-registration that allowed comparison of images over different time frames. These processes minimized the impact of non-surface 
factors such as imaging and viewing conditions, image mis-registration and atmospheric condition, on subsequent image analysis procedures (Furby and Campbell, 2001; Schott et al., 1988).

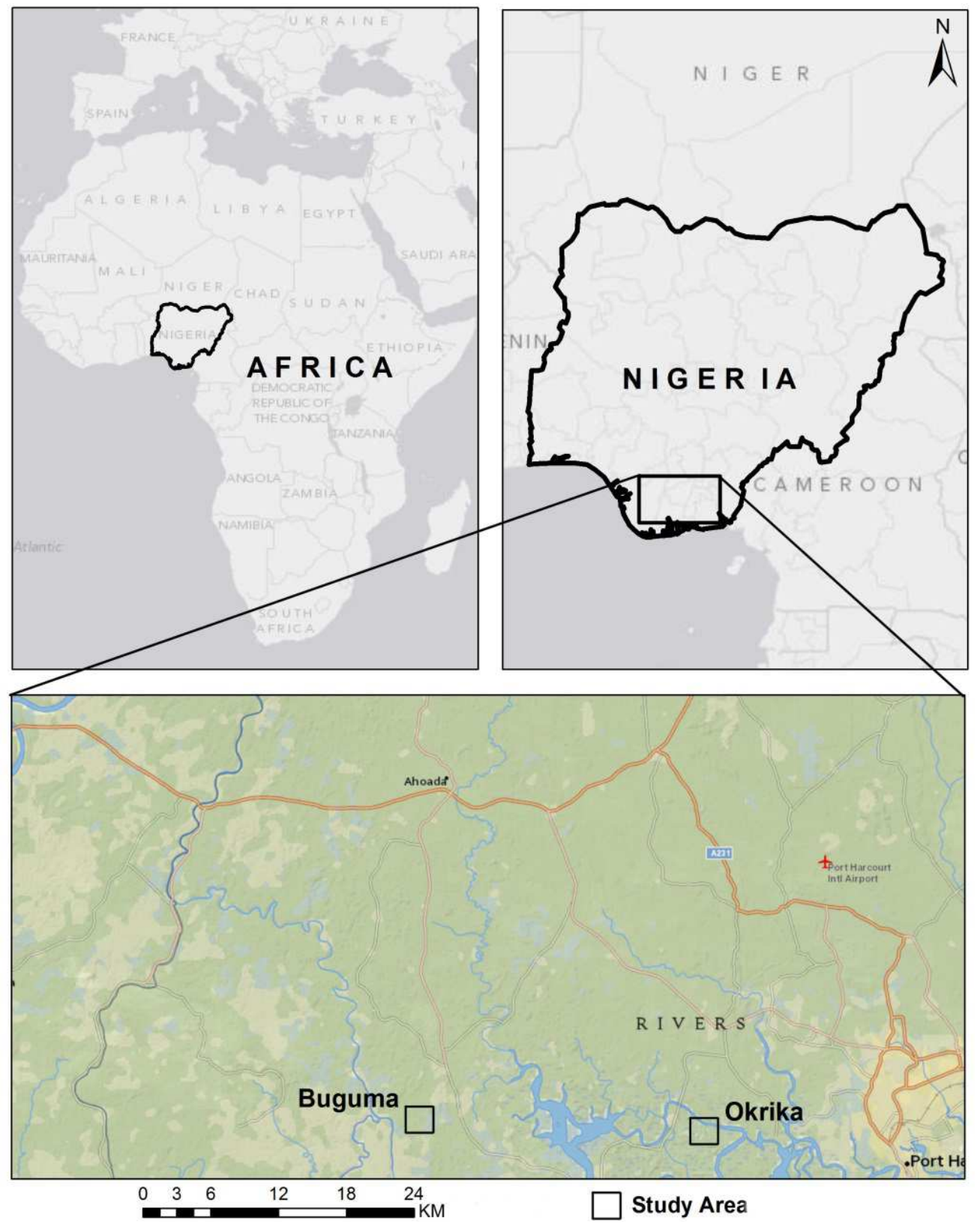

Fig. 1. Map of study area, Niger River Delta, Nigeria

Table 1. Satellite images of Niger River Delta acquired from USGS Earth Resources Observation and Science Center Landsat archive

\begin{tabular}{lllll}
\hline No. & Sensor & Cloudy conditions & Presence of gap & Acquisition date \\
\hline 1 & TM5 & cloud free & No & $1984 / 12 / 13$ \\
2 & TM5 & cloud free & No & $1986 / 12 / 19$ \\
3 & ETM7 & some cloud along the coast & No & $2000 / 12 / 17$ \\
4 & ETM7 & some cloud along the coast & No & $2003 / 01 / 08$ \\
5 & ETM7 & cloud free & Yes & $2005 / 01 / 13$ \\
6 & ETM7 & cloud free & Yes & $2007 / 01 / 19$ \\
\hline
\end{tabular}


Image geometric correction was only performed on the 1984 image while the rest datasets were provided with geometric correction already implemented. The 2003 image was used as a reference image to co-register the 1984 image using a second-order polynomial transformation with a root mean square error of less than one pixel. Also, cloud and cloud shadow was removed from the images collected in 2000 and 2003. The maximum likelihood classification method was used to extract cloud class, which removed most of the thick, thin and fringe clouds. We observed that the spectral character of the shadow was very similar to that of the wet mud in the study area. The shadow also had similar shape and relatively fixed location with the clouds. We therefore did not use spectral analysis to directly extract the shadow; rather we extracted the cloud shadow and wet mud together as a mixed class using supervised classification. We further used the cloud to spatially extract shadow from the mixed class. Another challenge was the unidentifiable nature of the shadows of the fringe clouds. Thus, in other to reduce exaggeration from the use of cloud class as the reference point in the extraction of shadow, we used decision tree (Friedl and Brodley, 1997) to separate clouds into thick and thin clouds and then identified shadow from the mixed class. To ensure the similarity of sizes for the temporal change analysis, we removed clouds and shadows from all the images.

\section{Image Classification}

The number and type of classes in a map is dependent on the information required and the availability of remotely sensed data used for classification (Kim et al., 2011). Two main forest types used in the research area were mangrove and mixed forest. They were validated by fieldwork and indicated that different mangrove species were not distinguishable in the middle scale satellite images of the Landsat data, unlike the Nypa palm species whose tree crowns were easily recognized from the Landsat images. Therefore, mangrove forest was separated into low and high-density mangrove, the palm stands within mixed forest were identified and a total of four coarse and nine fine classes were used in the classification (Table 2).

We derived the training area and then carried out the classification, with data got from fieldwork and a high resolution Geoeye image in Google Earth (acquisition date of June 11, 2010;50 cm spatial resolution). Two processes used to develop training areas across images were (i) overlaying of the training areas on all images and (ii) the use of $n-D$ Visualizer to check the separability of each class and clustering the purest pixels of each class. Pixels were used as the training samples because we cannot separate palm from mixed forest samples in 1984 and 1986 images, thus there was no palm class in these two images. The training samples were divided into two parts, 60 and $40 \%$ in a random manner. The larger portion $(60 \%)$ was used as input for supervised classifications, while the smaller portion $(40 \%)$ was used to test classification accuracy as ground truth pixel. Spectral Angle Mapper (Moughal and Yu, 2014) method was applied to classify the six images.

The classification accuracy was assessed by kappa coefficient, which is calculated by multiplying the total number of pixels in all the ground truth classes $(N)$ by the sum of the confusion matrix diagonals, subtracting the sum of the ground truth pixels in a class times the sum of the classified pixels in that class summed over all classes and dividing by the total number of pixels squared minus the sum of the ground truth pixels in that class times the sum of the classified pixels in that class summed over all classes of each put formula (Cohen, 1960; Rosenfield and Fitzpatrick-Lins, 1986).

Table 2. Classification schema for images of the mangrove landscape in the Niger River Delta

\begin{tabular}{|c|c|c|c|}
\hline Class name & Description & Plant species & Large class \\
\hline Mang 1 & high-density mangrove forest. & Rhizophora mangle, $R$. germinans, & \\
\hline Mang 2 & low-density mangrove forest. & R. racemosa & Mangrove \\
\hline Mixed & $\begin{array}{l}\text { Mixed forests are species of mangrove, } \\
\text { palm and other tree species }\end{array}$ & $\begin{array}{l}R . \text { mangle, } R \text {. germinans, } R \text {. racemosa, } \\
N . \text { fruticans, Chrysobalanus icaco }\end{array}$ & Mixed \\
\hline palm $^{\mathrm{a}}$ & Nypa palm and mixed forests & N. fruticans & \\
\hline Water & $\begin{array}{l}\text { Ponds, creeks, rivers and oceans, } \\
\text { low reflectance bands }\end{array}$ & - & wetland \\
\hline Wet-mud & $\begin{array}{l}\text { Saturated soil, rivers, creeks, swamps, } \\
\text { low reflectance bands. }\end{array}$ & - & \\
\hline Urban & $\begin{array}{l}\text { County, town or city with constructions, } \\
\text { roads, etc. }\end{array}$ & - & Urban-region \\
\hline Urban-veg & $\begin{array}{l}\text { Wild vegetation between urban area and } \\
\text { mangrove zone. }\end{array}$ & $\begin{array}{l}\text { Corn vine (Dalbergia eccastophylum), } \\
\text { fern, silt grass (Paspalum vaginatum), etc. }\end{array}$ & \\
\hline Bare-land & $\begin{array}{l}\text { Bare land created by human activities; high } \\
\text { reflectance in visual and short wave infrared }\end{array}$ & & \\
\hline
\end{tabular}

NB: ${ }^{a}$ The palm class was not separated from mixed class in 1984 and 1986 images 


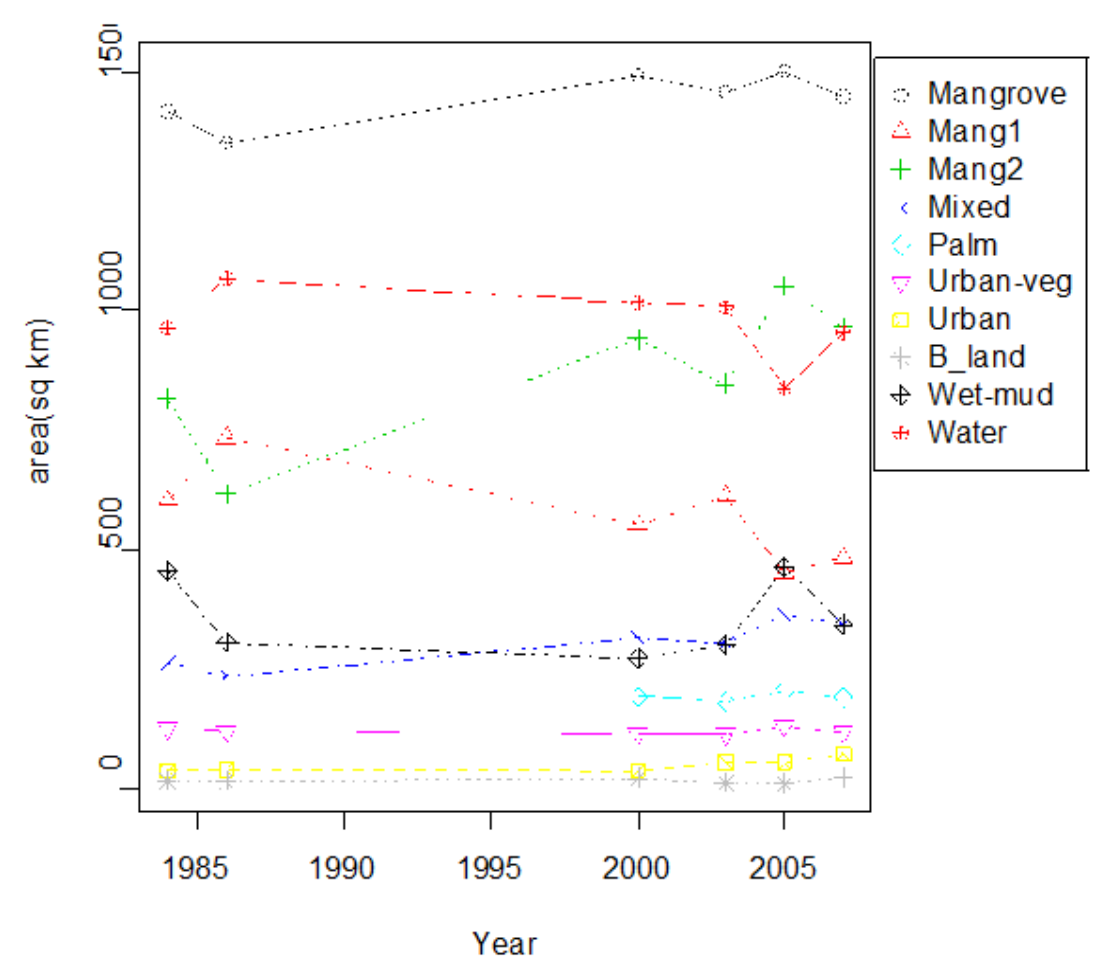

Fig. 2. Mangrove landscape pattern and changes from 1984 to 2007 derived from different land cover types

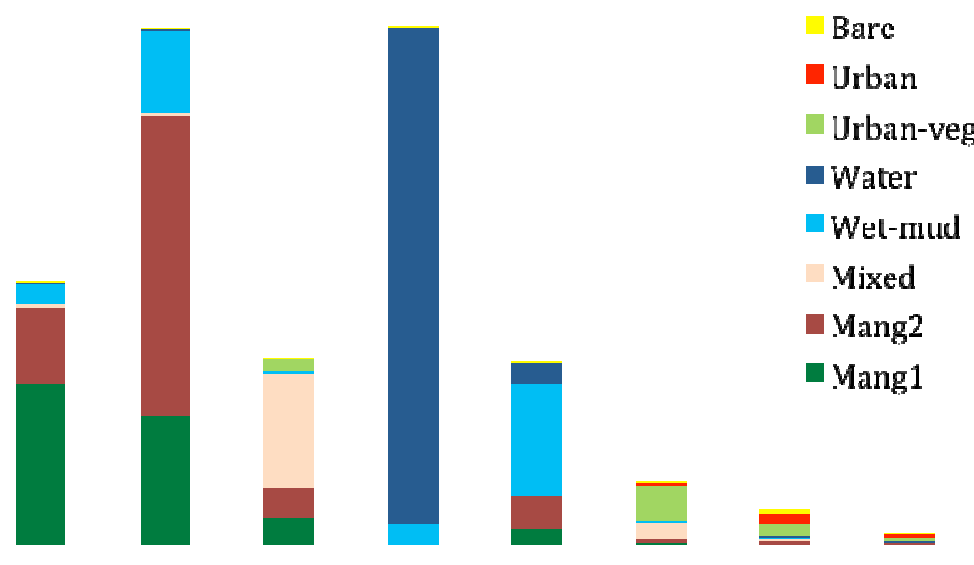

Fig. 3. Spatial locational shift of every land cover type in Niger River Delta mangrove landscape from 1984 to 2007 . The colors represent the original year's land cover type; the bars represent the final year's land cover type. Since there was no Palm in 1984 images classification the change in palms was not analyzed

\section{Mangrove Landscape Change Analysis}

The area of each cover type from the image classification results was measured in order to track mangrove landscape changes through time (Fig. 2). The average area, average proportion, standard deviation and coefficient of variation among sites were calculated for each cover type in the past six years. The correlation coefficients of mangrove forest and other land cover types were also calculated to show the relationships in the past six years. Change detection techniques were then used to detail spatial dynamics of mangrove landscape from 1984 to 2007 (Fig. 3).

To analyze the impact of oil and gas exploration on the spatial structure of the mangrove landscape, square samples of $6.76 \mathrm{~km}^{2}$, were extracted randomly from the study area and separated into high and low exploration areas, with the samples that crossed the boundary deleted. To analyze the spatial relationship between mangrove forest and mixed forest, round samples around square 
samples were extracted, with the same area and centric coordinates. Therefore, at each sample position a pair of sample was chosen, one square and the other round using ESRI ArcGIS 9.3 (ESRI, 2009, Redlands, CA, USA).

We mainly focused on the land cover and deleted pairs of samples with 'water' coverage greater than $50 \%$ or 'mask' coverage greater than $20 \%$. The average sample size derived was 145 , with high exploration (86) and low exploration (59). The 'mask' coverage of every sample was not equal, so the proportion of every land cover type in every sample was re-calculated after the removal of the 'mask'. This work was carried out in the program R 2.13.0 (RDCT 2010).

\section{Statistical analysis}

Parametric statistics are based on the assumption of independence of the individual observations in the data (Fortin and Dale, 2014), however there is usually spatial autocorrelation in landscape test (Legendre, 1993). We therefore, used Moran's I test to evaluate spatial autocorrelation of land cover types (Table 3 ). The null hypothesis of this test was a random distribution pattern. The IDW B spatial weight was used, the lower and upper distance bounds were 0 and 1.5 times max distance of $\mathrm{k}$ nearest neighbor objects $(\mathrm{k}=1)$. Spatial autocorrelation was removed via spatial trend modeling, in which the coverage rate of every land cover type in square samples was the dependent variable and latitude and longitude of samples were the factor variables.

A randomized Block ANOVA was performed to test differences between high and low exploration sites for all land cover types, blocked by year (Table 4). A Geographical Linear Model (GLM) was conducted to quantify the impact of exploration on different land cover types (Table 4). In these models, the coverage rate of every land cover type in square samples was the dependent variable, while the exploration state and year were the factor variables and year was a blocking factor. The spatial relationship between mangrove forest and mixed forest and the impact of exploration on this spatial relationship was estimated by GLM, while year was used as a blocking factor. To remove the proportion effect on this analysis, the coverage rate of Mangrove forest and Mixed forest was calculated in square and round samples respectively. In the GLM the coverage rates of Mangrove, Mang 1 and Mang 2 in square samples were used as dependent variable respectively, while the coverage rates of Mixed forest in round samples, exploration state, year and the interaction between mixed forest and exploration states were used as independent variables.

Table 3. Moran's (autocorrelation) test for main land cover types in the Niger River Delta mangrove landscape from 1984 to 2007

\begin{tabular}{llllllll}
\hline Land covecover & Moran's test & 1984 & 1986 & 2000 & 2003 & 2005 & 2007 \\
\hline Mangrove & Moran's I & 0.09 & 0.16 & 0.09 & 0.05 & 0.04 & 0.05 \\
& $p$ & $<0.001$ & $<0.001$ & $<0.05$ & $<0.05$ & 0.22 & $<0.01$ \\
Mang 1 & Moran's I & 0.12 & 0.16 & 0.16 & 0.03 & -0.06 & 0.001 \\
& $p$ & $<0.001$ & $<0.001$ & $<0.001$ & 0.12 & 0.23 & 0.72 \\
Mang 2 & Moran's I & 0.02 & 0.05 & 0.24 & 0.10 & 0.07 & 0.06 \\
& $p$ & 0.29 & $<0.05$ & $<0.001$ & $<0.001$ & 0.06 & $<0.01$ \\
Mixed & Moran's I & 0.08 & 0.09 & 0.11 & 0.06 & 0.11 & 0.13 \\
& $p$ & $<0.001$ & $<0.001$ & $<0.01$ & 0.01 & $<0.01$ & $<0.001$ \\
Palm & Moran's I & -- & -- & 0.03 & 0.02 & 0.11 & 0.11 \\
& $p$ & -- & -- & 0.39 & 0.39 & $<0.01$ & $<0.001$ \\
Wet-mud & Moran's I & 0.07 & 0.13 & 0.08 & 0.04 & 0.1 & 0.04 \\
& $p$ & $<0.001$ & $<0.001$ & $<0.05$ & $<0.05$ & 0.01 & $<0.05$ \\
Urban-region & Moran's I & 0.04 & 0.08 & 0.18 & 0.03 & 0.19 & 0.06 \\
& $p$ & 0.09 & $<0.001$ & $<0.001$ & 0.12 & $<0.001$ & $<0.001$ \\
\hline
\end{tabular}

NB: “--” there are no palm class in 1984 and 1986 images.

Table 4. Randomized Block ANOVA a and GLM for oil and gas exploration's impact in the Niger River Delta mangrove landscape from 1984 to 2007

\begin{tabular}{lllllllll}
\hline Source & & Mangrove & Mang 1 & Mang 2 & Mixed & Palm $^{\mathrm{b}}$ & Wet-mud & Urban-region \\
\hline High exploration & $d f$ & 1 & 1 & 1 & 1 & 1 & 1 & 1 \\
& $F$ & 1.82 & 40.56 & 9.15 & 14.75 & 6.97 & 33.72 & 16.14 \\
& Coefficient & -0.11 & -0.56 & 0.18 & -0.52 & -0.37 & -0.35 & 0.53 \\
Year & $p$ & 0.178 & $<0.001$ & $<0.01$ & $<0.001$ & $<0.01$ & $<0.001$ & $<0.001$ \\
& $d f$ & 5 & 5 & 5 & 5 & 3 & 5 & 5 \\
& $F$ & 2.35 & 8.39 & 19.87 & 7.92 & 3.59 & 12.42 & 1.75 \\
Residual & $p$ & $<0.05$ & $<0.001$ & $<0.001$ & $<0.001$ & $<0.05$ & $<0.001$ & 0.12 \\
\end{tabular}

${ }^{\mathrm{a}}$ The blocks were different years; ${ }^{b}$ No palm class in 1984 and 1986 images, so the $d f$ was lower 
Moran's I test, averages and standard deviations were calculated from original proportional data and all the spatial trend models analyses were performed on modified $\log$ transformed data, i.e., $\log (\mathrm{y}+\varepsilon /[1-\mathrm{y}+\varepsilon])$, $\varepsilon=0.01$ (Warton and Hui, 2011). The ANOVA and GLM were performed on the residuals of spatial trend model. All the statistical analyses were carried out in the $\mathrm{R}$ 2.13.0 program. The residuals from the ANOVA and GLM were normally distributed, suggesting that these models were appropriate.

\section{Results}

\section{Landscape Pattern and Change}

We assessed the classification accuracy by calculating the kappa coefficients of the six images, which were all greater than 0.9 (i.e., 0.93, 0.07, 0.94, $0.93,0.90$ and 0.94 for the six different years respectively) indicating that the classification process was correct and the accuracy high. Landscape changes were then estimated by determining the proportion of the different land cover types. Mangrove forest was the major land cover and its average proportion and area was $42.0 \%$ and $1444.7 \mathrm{~km}^{2}$ respectively, out of which Mang 1 was $16.6 \%$ and $572.4 \mathrm{~km}^{2}$ and Mang 2 was $25.4 \%$ and $872.3 \mathrm{~km}^{2}$ (Fig. 2). The average proportion of Water and Wet-mud were 28.3 and $10.4 \%$, while their average areas were $974.5 \mathrm{~km}^{2}$ and $356.7 \mathrm{~km}^{2}$ respectively. As for Mixed forest, the average proportion and average area was $8.9 \%$ and $304.5 \mathrm{~km}^{2}$, while palm was $5.6 \%$ and $192.9 \mathrm{~km}^{2}$ respectively. The palm took almost two third of the mixed forest. Lastly, Urban-region, which includes construction, road, urban vegetation, etc., was $5.4 \%$ and $185.7 \mathrm{~km}^{2}$ respectively.

We did not discover any major temporal changes in mangrove forests from 1984 to 2007 and in addition the fluctuation was also relatively small (Fig. 2). This is supported by the fact that the mangrove variation coefficient was the lowest (0.038), which means that its occurrence was more consistent than other land cover types identified in this study. On the contrary, the variation coefficient of Mang 1 (0.178) and Mang 2 (0.174), which indicated that both of them had an obvious changing trend, with the former decreasing while the later was increasing. These two land cover types show a strong negative relationship, with their correlation coefficient $(-0.96)$. This means that even though the total area of mangrove did not change much, the biomass of mangrove did decrease. Furthermore, Mixed forest and palm increased from 1984 to 2007 and all had strong negative relationship with Mang 1 and strong positive relationship with Mang 2. Lastly, Urbanregion also increased during these years and had negative relationship with both Mangrove and Mang 1 and positive relationship with Mang 2.

Spatial change detection statistic showed that mangrove landscape had a large spatial locational shift from 1984 to 2007 (Fig. 3). During this period, more than one third of Mang 1, Mang 2, Mixed forest and Wet-mud were converted from one land cover type to another from the bottom to the top of the bar.

\section{Spatial Relationship Analyses}

Spatial autocorrelation test was performed by Moran's test (Table 3). Seventy-nine percent (79\%) of Moran's tests were significant and most of the indices were positive, but much lower than one. This indicates that most land cover type had weak global spatial autocorrelation and were weakly clustered. We also found that even Moran's I of Mang 2 increased from 1984 to 2000. Furthermore, we observed that the total trend of Moran's I of Mangrove forest decreased during the last year (2007).

There was an obvious land cover pattern difference between high and low exploration areas (Fig. 4). The coverage rates of Mang 1, Mixed, palm and Wet-mud were higher in low exploration area when compared to urban region. However, the difference of Mang 2 between high and low exploration areas was difficult to determine. High exploration had very significant and negative effect on Mang 1, Mang 2, Mixed forest, palm, Wet-mud and Urban region (Table 4). On the contrary, positive effects were observed in Mang 2 and urban region (Table 4). Nevertheless, high exploration did not significantly affect the total area of Mangrove $\left(\mathrm{F}_{1,865}=1.82, p=0.178\right.$; Fig. $5)$. Even though, high exploration did not affect total area of mangrove, it is not good for high or low-density forest types as it strongly decreases the density of mangrove forest. While, years also had significant influence on most land cover types with the exclusion of Urban-regions $\left(\mathrm{F}_{5,865}=1.75, p=0.12\right.$; Table 4).

Table 5. Spatial relationship between mangrove forest and Mixed forest in the Niger River Delta mangrove landscape from 1984 to 2007

\begin{tabular}{lllll}
\hline Variable & & Mangrove & Mang 1 & Mang 2 \\
\hline Mixed & Coefficient & -0.31 & -0.18 & -0.15 \\
& $p$ & $<0.001$ & $<0.001$ & $<0.001$ \\
High exploration state & Coefficient & -0.24 & -0.62 & 0.09 \\
& $p$ & $<0.01$ & $<0.001$ & 0.099 \\
Mixed $\times$ high exploration state & Coefficient & 0.12 & 0.18 & -0.07 \\
& $p$ & $<0.001$ & $<0.001$ & $<0.05$ \\
\hline
\end{tabular}




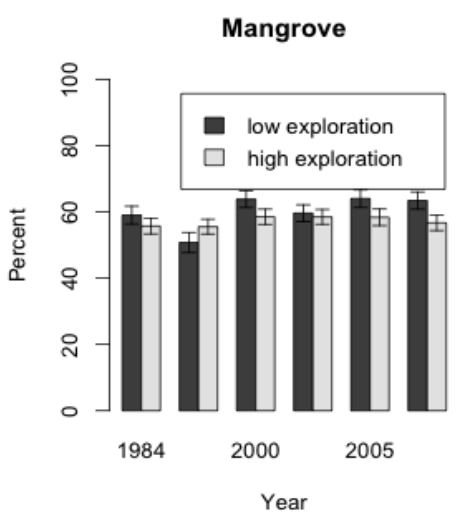

Mang2

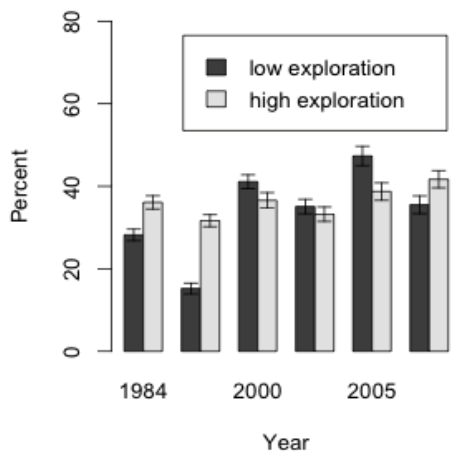

Wet-mud

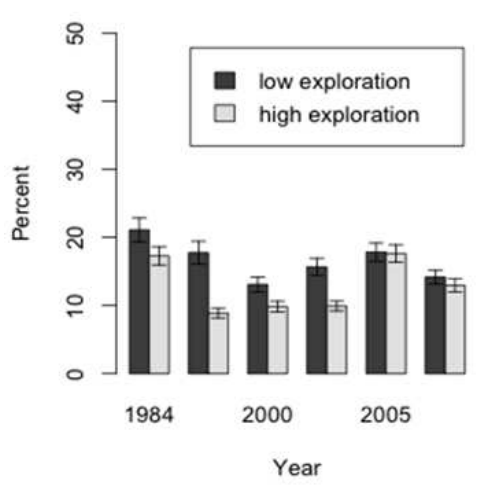

Mang1

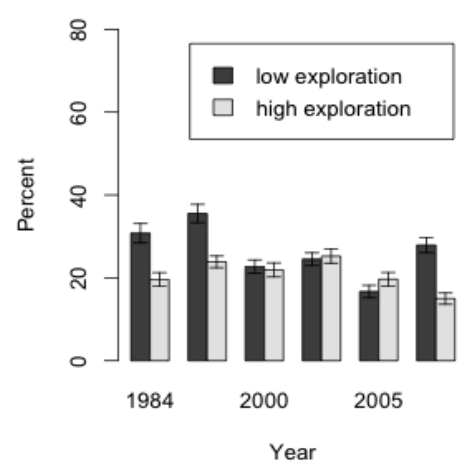

Mixed

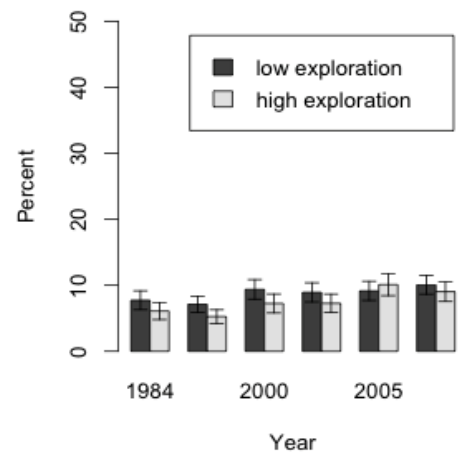

Urban region

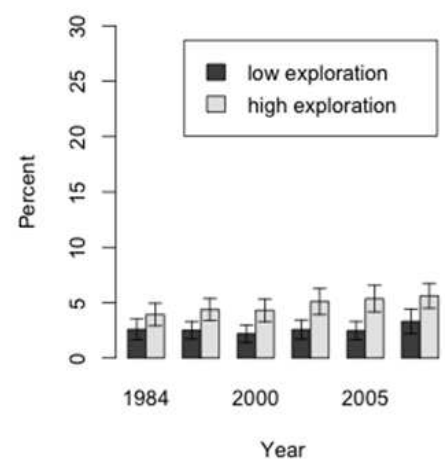

Palm

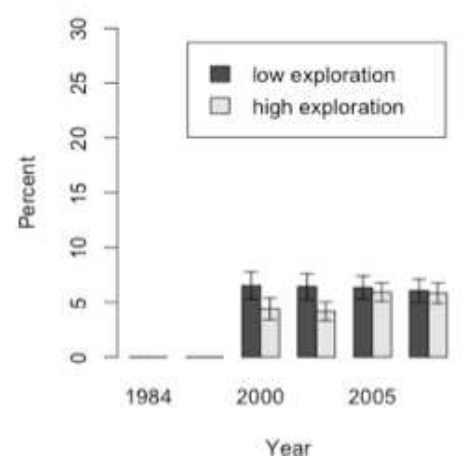

Fig. 4. Mean percent coverage rates and standardized deviation (+ SE) of main land cover types in high and low exploration areas in Niger River Delta mangrove landscape from 1984 to 2007 


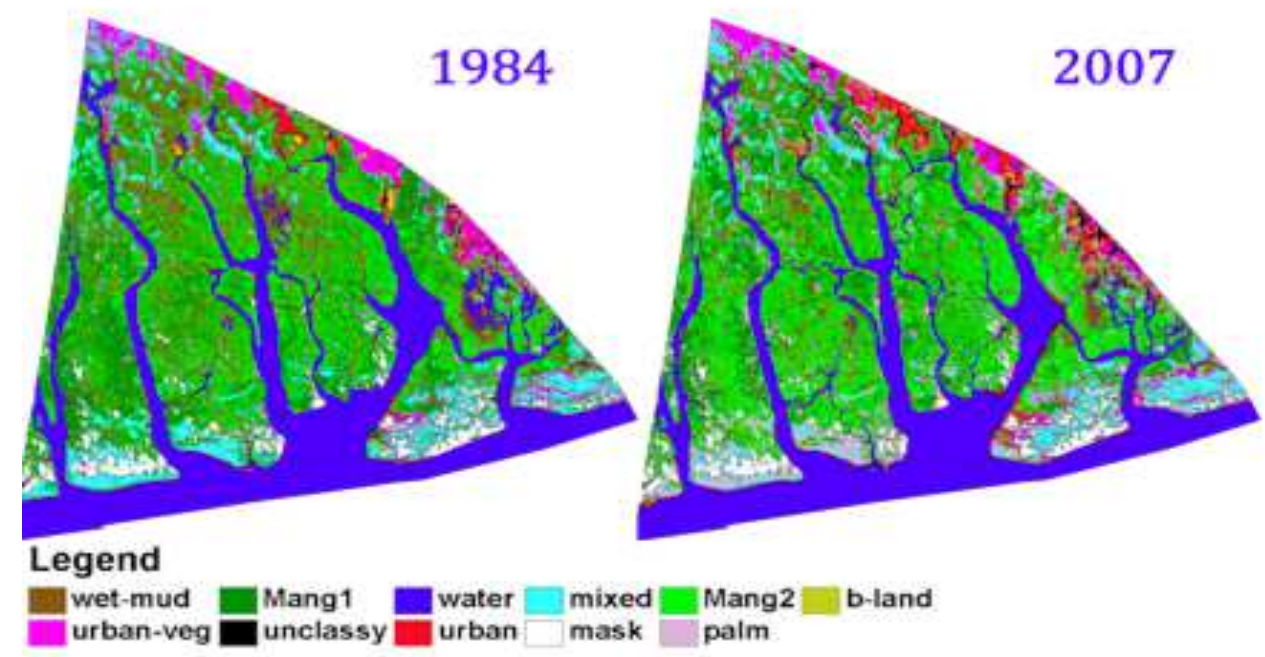

Fig. 5. Mangrove changes in the Niger River Delta, Nigeria from 1984 to 2007

Mangrove, Mang 1 and Mang 2 had significant negative relationship with Mixed (Table 5). The high exploration has significant positive effect on two relationships, i.e., Mangrove and Mixed, while on the other hand it has significant negative effect on the relationship of Mang 2 and Mixed. In the high exploration area the relationship between mangrove and Mixed, Mang 1 and Mixed and Mang 2 and Mixed are $0.19,0$ and -0.22 respectively.

\section{Discussion}

\section{Landscape Pattern and Change}

The total area of mangrove did not change drastically, but the biomass did decrease significantly (Fig. 2). Meanwhile, the Mixed forest increased and its expansion contributed to the decrease of mangrove biomass. It was difficult for the Landsat images to differentiate between Nypa palm (Nypa fruticans) and oil palm (Elaeis gueneensis), however, through field work it was found that Nypa palm was the most dominant palm species in the study area. Apart from the Mixed forest, the Urban-region also increased rapidly over the years as a result of urbanization, which had contributed to the decline in the total area and biomass of mangrove (Fig. 2). Other studies in the Niger Delta (e.g., James et al., 2007) have also reported similar result. Though both studies had differences in changes in the total area of mangroves, their outcome still reflects a slow and steady decline over the years. Our study had a $4 \%$ decrease in mangroves, while James et al. (2007) had less than $5 \%$ decrease. Other global studies have shown a general decline in the total area of mangroves (Finlayson et al., 1999; Giri et al., 2011; Spalding et al.,
1997; Valiela et al., 2001). Different parts of the world have different rates of mangrove changes (Giri and Muhlhausen, 2008), due to site-specific factors such as landscape and weather systems (Llopart et al., 2014), salinity (Gilman et al., 2008) and land accretion, etc. However, percentage mangrove decline in other areas of the world with constant turbulent weather like hurricane and tsunami were higher (Alongi, 2008; Doyle et al., 1995). In addition, changes in climate circulation leading to seasonal changes can impact the growth of mangroves (Dai et al., 2009). Similarly, logging (Alongi, 2008), oil pollution (Duke et al., 1997; Kathiresan and Bingham, 2001) and harvesting (Udofia and Udo, 2005) can lead to decline in mangrove biomass.

The spatial change detection statistic shows that mangrove being the main land cover type has not only changed its area of distribution, but has also undergone spatial locational shift. The result of the spatial autocorrelation test (Table 3 ) indicates that the cluster of mangrove forest has decreased (e.g., Mang 1) possibly due to deforestation, pollution and urbanization. To explain these phenomena further we may need more studies on landscape patch analysis such as patch area, patch edge and patch connectivity of urban areas around the mangroves.

\section{Effect of Oil and Gas Exploration}

Regions with high oil and gas exploration had significantly decreased density of mangrove and mixed forest. This is because oil pollution damages mangrove and other tree species in the Niger delta (Snowden and Ekweozor 1987; Osuji et al., 2004). A challenge in using Landsat is the difficulty in detecting oil spill on land or water, especially with the presence of dense forests. This problem was however, resolved using ground truthing at 
the study site where we found that high exploration increased urban-region and decreased wet-mud. Reduction in the size of the wet-mud shows that the swampy mangrove areas in the Niger Delta is quickly being over-taken by construction of social amenities and engineering activities brought about by the influx of oil companies prospecting for crude oil. These exploratory activities convert the swampy soil to sandy soil that encourages the proliferation of non-mangrove species such as corn vine (Dalbergia ecastophylum) and silt grass (Paspalum vaginatum). Pollution in the study area causes the yellowing and defoliation of leaves, suffocation and death of propagules, trees and other mangrove ecosystem inhabitants (e.g., fish, crabs and periwinkle). Previous studies have attributed the loss of $210 \mathrm{~km}^{2}$ of mangrove as a result of urbanization, dredging and oiling activities (James et al., 2007). Therefore, landscape change is an estimate of the direct or indirect impact of oil and gas exploration, which is a combination of both chemical pollution and physical disturbances.

\section{Spatial Relationships between Mangrove and Mixed Forest}

Mangrove and Mixed forest have negative and nonrandom relationship, which implies that Mixed forest is a threat to the stability of mangroves. The Nypa palm being an invasive species thrives when there is a disturbance such as oil pollution (Crooks et al., 2010). This is because invasive species have superior genetic qualities than the native species (Stastny et al., 2005). Land degradation (Alongi, 2008) and habitat modification (Ellison, 1993) also affect the growth of mangroves and leads to the increase in mixed forest. In this study, we found that people living around coastal areas often dump their waste in the mangrove forests, which later lead to increase in land elevation. Similarly, the dredging of the swamp for land reclamation introduces sandy soils, which kills the mangroves and creates bare-land (Table 2).

In high exploration area high-density mangrove (Mang 1) withstood the impact of exploration better than mixed forests and Mang 2. Mixed forests have less negative impact on Mang 1, when compared to Mang 2. Furthermore, Mang 2, had the least ability to withstand exploration than the mixed forest, which implies that the overall ability of mangrove forest to withstand high exploration is dependent on forest density. Therefore, the destruction of forests by logging, pollution, agriculture and urbanization decrease the extent of mangrove biomass, leading to the decrease in its ability to withstand disturbances generated by other environmental perturbations (Alongi, 2008). More studies are however, needed to determine the density effect of mangroves identified by this study.

\section{Conclusion}

The Landsat remote sensing showed the impact of oil and gas exploration through pollution, invasion and urbanization. Mangrove total area may not always change drastically, but might change in biomass leading to increase in low density mangrove forests. Increase in industrial and human activities result to the increase in establishment of social amenities in mangrove areas, which resulted to the decrease in mangrove population. It is therefore, more beneficial to have highly dense than sparsely populated mangrove. Invasion and urbanization have negative relationship with mangroves. We thus, suggest a win-win conservation system that will ensure a balance between mangrove forest restoration and utilization.

\section{Acknowledgement}

The authors thank Dr. Abdulwasit Wulamu of the Department of Sustainability, Saint Louis University for his assistance in remote sensing. We also thank Dr. Eric Westhus, Saint Louis University for his assistance in $R$ statistics. We thank Drs. Life Kaanagbara and Patrick Nabien for reviewing the manuscript.

\section{Funding Information}

The researchers did not receive any funds from any funding agency for this project. The study was independently carried out by the authors at the Saint Louis University, Missouri GIS laboratory and the field station in Niger River Delta, Nigeria.

\section{Author's Contributions}

Ping Wang: Contributed in experiments design, remote sensing, analysis and interpretation and manusript writing.

Aroloye O. Numbere: Data collection, georeferencing and provision of environmental data of study area and also contributed in manuscript writing.

Gerardo R. Camilo: Initiated the conceptual design, performed the statistical analysis and supervised the project and was involved in all aspect of the work.

\section{Ethics}

This article is original and contains unpublished material. The corresponding author confirms that all of the other authors have read and approved the manuscript and no ethical issues involved.

\section{Conflict of Interest}

None of the authors has any conflict of interest to declare. 


\section{References}

Alongi, D.M., 2008. Mangrove forests: Resilience protection from tsunamis and responses to global climate change. Estuarine Coastal Shelf Sci., 76: 1-13. DOI: 10.1016/j.ecss.2007.08.024

Anwar, S.M. and S. Takewaka, 2014. Analyses on phenological and morphological variations of mangrove forests along the southwest coast of Bangladesh. J. Coastal Conserv., 18: 339-357. DOI: $10.1007 / \mathrm{s} 11852-014-0321-4$

Burns, K.A., S.D. Garrity, D. Jorrisen, J. MacPherson and M. Stoelting et al., 1994. The Galeta oil spill; II, Unexpected persistence of oil trapped in mangrove sediments. Estuarine Coastal Shell Sci., 38: 349-364. DOI: 10.1006/ecss.1994.1025

CEDA, 1997. Coastal profile of Nigeria. Federal Environmental Protection Agency, Press, Abuja, Nigeria.

Cohen, J., 1960. A coefficient of agreement of nominal scales. Educ. Psychol. Measure., 20: 37-46. DOI: $10.1177 / 001316446002000104$

Colwell, R.N., 1997. History and Place of Photographic Interpretation. In: Manual of Photographic Interpretation, W.R. Philipson (Ed.). American Society of Photogrammetry and Remote Sensing, Bethesda Maryland USA, pp: 3-47.

Crooks, J.A., A.L. Chang and G.M. Ruiz, 2010. Aquatic pollution increases the relative success of invasive species. Biol. Invas., 13: 165-176. DOI: $10.1007 / \mathrm{s} 10530-010-9799-3$

Dai, A., T. Qian, K.E. Trenberth and J.D. Millman. 2009. Changes in continental freshwater discharge from 1948 to 2004. J. Climate, 22: 2773-2779. DOI: $10.1175 / 2008$ jcli2592.1

Doyle, T.W., T.J. Smith III and M.B. Robblee, 1995. Wind damage effects of hurricane Andrew on mangrove communities along the southwest coast of Florida, USA. J. Coastal Res., 21: 159-168.

Dublin-Green, C.O., 1993. The foraminiferan fauna of Bonny estuary, a baseline studies. NIOMR Technical Paper.

Duke, N.C., M.Z.S. Pinzon and T.M.C. Prada, 1997. Large-scale damage to mangrove forests following two large oils spills in Panama. Biotropica, 29: 2-14. DOI: $10.1111 /$ j.1744-7429.1997.tb00001.x

Ellison, J.C., 1993. Mangrove retreat with rising sea level. Bermuda. Estuarine Coastal Shelf Sci., 37: 7587. DOI: $10.1006 /$ ecss.1993.1042

ESRI, 2009. ArcGIS Desktop: Release 9.3. Environmental Systems Research Institute. Redlands, CA, USA.

Finlayson, C.M., N.C. Davidson, A.G. Spiers and N.J. Stevenson, 1999. Global wetland inventorycurrent status and future priorities. Marine Freshwater Res., 50: 717-727. DOI: 10.1071/MF99098
Fortin, M.J. and M.R.T. Dale, 2014. Spatial Analysis a Guide for Ecologists. 2nd Ed. Cambridge University Press, ISBN-13: 9780511978913 , pp: 125.

Friedl, M. and C. Brodley, 1997. Decision tree classification of land cover from remotely sensed data. Remote Sens. Environ., 61: 399-409.

DOI: 10.1016/s0034-4257(97)00049-7

Furby, S.L. and N.A. Campbell, 2001. Calibrating images from different dates to 'like value' digital counts. Remote Sens. Environ., 77: 186-196. DOI: 10.1016/S0034-4257(01)00205-X.

Gilman, E.L., J. Ellison, V. Jungblut, H. Van Lavieren and L. Wilson et al., 2006. Adapting to Pacific island mangrove responses to sea level rise and climate change. Climate Res., 32: 161-176. DOI: $10.3354 / \mathrm{cr} 032161$

Gilman, E.L., J. Ellison, N.C. Duke and C. Field, 2008. Threats to mangroves from climate change and adaptation options: a review. Aquatic Botany, 89: 237-250. DOI: 10.1016/j.aquabot.2007.12.009

Giri, C. and J. Muhlhausen, 2008. Mangrove forest distributions and dynamics in Madagascar (19752005). Sensors, 8: 2104-2117. DOI: $10.3390 / \mathrm{s} 8042104$

Giri, C., E. Ochieng, L.L. Tieszen, Z. Zhu and A. Singh et al., 2011. Status and distribution of mangrove forests of the world using earth observation satellite data. Global Ecol. Biogeography, 20: 154-159. DOI: $10.1111 / \mathrm{j} .1466-8238.2010 .00584 . \mathrm{x}$

Hayden, H.L and E.F. Granek, 2015. Coastal sediment elevation change following anthropogenic mangrove clearing. Estuarine Coastal Shelf Sci., 165: 70-74. DOI: $10.1016 /$ j.ecss.2015.09.004

Hewitt, G.M., 2004. Genetic consequences of climatic oscillation in the quaternary. Biol. Sci., 359: 183-195. DOI: $10.1098 /$ rstb.2003.1388

James, G.K., J.O. Adegoke, E. Saba, P. Nwilo and J. Akinyede, 2007. Satellite-based assessment of the extent and changes in the mangrove ecosystem of the Niger Delta. Marine Geodesy, 30: 249-267. DOI: $10.1080 / 01490410701438224$

Kathiresan, K. and B.L. Bingham, 2001. Biology of mangrove ecosystems. Adv. Marine Biol., 40: 81-251. DOI: 10.1016/s0065-2881(01)40003-4

Keay, R.W.J., C.F.A. Onochie and D.P Standfield, 1964. Nigerian trees. Federal Department of Forestry Research, National Press Limited, Ibadan, Nigeria.

Kim, S.R., W.K. Lee, D.A. Kwak, G.S. Biging and P. Gong et al., 2011. Forest cover classification by optimal segmentation of high resolution satellite imagery. Sensors, 11: 1943-1958. DOI: $10.3390 / \mathrm{s} 110201943$

Legendre, P., 1993. Spatial autocorrelation: Trouble or new paradigm? Ecology, 74: 1659-1673. DOI: $10.2307 / 1939924$ 
Llopart, M., E. Coppola, F. Giorgi, R.P. da Rocha and S.V. Cuadra, 2014. Climate change impact on precipitation for the Amazon and La Plata basins. Climatic Change, 125: 111-125.

DOI: $10.1007 / \mathrm{s} 10584-014-1140-1$

Lu, D., P. Mausel, E. Brondizio and E. Moran, 2002. Assessment of atmospheric correction methods for Landsat TM data applicable to Amazon basin LBA research. Int. J. Remote Sens., 13: 2651-2671. DOI: $10.1080 / 01431160110109642$

Moughal, T.A. and F. Yu, 2014. An Automatic Unsupervised Method Based on Context-Sensitive Spectral Angle Mapper for Change Detection of Remote Sensing Images. In: Advanced Data Mining and Applications, Luo, X. and J.X. Yu (Eds.), Springer International Publishing, Switzerland, ISBN-13: 978-3-319-14717-8, pp: 151-162.

NDES, 1997. Environmental and socio-economic characteristics, second phase of field re-port. Environmental Resource Manager Limited. Nigeria Country Analysis Brief 2005. Report published by the Energy Information Administration (EIA), USA Government Department of Energy.

Nwilo, P., 2004. GIS Applications in Coastal Management: A View from the Developing World. In: GIS for coastal zone management, Smith, $\mathrm{J}$ and D. Bartlett (Eds.). CRC Press LLC, ISBN: 978-0-415-31972-0.

Nwilo, P.C. and O.T. Badejo, 2005. Oil spill problems and management in the Niger delta. Int. Oil Spill Proc., 2005: 567-570.

DOI: $10.7901 / 2169-3358-2005-1-567$

Olsen, D.M. and E. Dinerstein, 2002. The global 200: Priority ecoregions for global conservation. Annals Missouri Botanical Garden, 89: 199-224. DOI: $10.2307 / 3298564$

Okoye, B.C.O., A.O. Afolabi and A.E. Ajao, 1991. Heavy metals in the Lagos lagoon sediments. Int. J. Environ. Stud., 37: 35-41. DOI: $10.1080 / 00207239108710641$

Osuji, L.C., S.O. Adesina and G.C. Obute, 2004. Post impact assessment of oil pollution in Agbada west plain of Niger Delta Nigeria: Field reconnaissance and total extractable hydrocarbon content. Chem. Biodiversity, 1: 1569-1577. DOI: $10.1002 / \mathrm{cbdv} .200490117$

Polidoro, B.A., K.E. Carpenter, L. Collins, N.C. Duke and A.M. Ellison et al., 2010. The loss of species: Mangrove extinction risk and geographic areas of global concern. PLoS ONE, 5: e10095-e10095. DOI:10.1371/journal.pone.0010095

RDCT, 2010. R: A language and environment for statistical computing. R Foundation for Statistical Computing, Vienna, Austria.
Rosenfield, G.H. and K. Fitzpatrick-Lins, 1986. A coefficient of agreement as a measure of thematic classification accuracy. Photogrammetric Eng. Remote Sens., 52: 223-227.

Schott, J.R., C. Salvaggio and W.J. Volchok, 1988. Radiometric scene normalization using pseudoinvariant features. Remote Sens. Environ., 26: 1-16. DOI: 10.1016/0034-4257(88)90116-2

Snowden, R.J. and I.K.E. Ekweozor, 1987. The impact of a minor oil spillage in the estuarine Niger Delta. Marine Pollut. Bull., 18: 595-599. DOI: $10.1016 / 0025-326 x(87) 90279-7$

Spalding, M.D., F. Blasco and C.D. Field, 1997. World Mangrove Atlas. The International Society for mangrove ecosystems, Okinawa.

Stastny, M., U.R.S. Schaffner and E. Elle, 2005. Do vigour of introduced populations and escape from specialist herbivores contribute to invasiveness? J. Ecol., 93: 27-37. DOI: $10.1111 / \mathrm{j} .1365-2745.2004 .00962 . \mathrm{x}$

Stokes, D.J. and R.J. Harris, 2015. Sediment properties and surface erodibility following a large-scale mangrove (Avicennia marina) removal. Continental Shelf Res., 107: 1-10. DOI: 10.1016/j.csr.2015.07.011

Turner, M.G., R.H. Gardner and R.V. O’Neil, 2001. Landscape Ecology: In theory and Practice Pattern and Process. Springer-Verlag, New York, Inc.

Udofia, S.I. and E.S. Udo, 2005. Local knowledge of utilization of Nipa palm (Nypa fruticans, Wurmb), in the coastal areas of Akwa Ibom, Nigeria. Global J. Agric. Sci., 4: 33-40. DOI: 10.4314/gjass.v4i1.2252

Ukpong, I.E., 1997. Vegetation and its relation to soil nutrient and salinity in the Calabar mangrove swamp, Nigeria. Mangroves Salt Marshes, 1: 211-218. DOI: 10.1023/a:1009952700317

Valiela, I., J.L. Bowen and J.K. York, 2001. Mangrove forests: One of the world's threatened major tropical environments. BioScience, 51: 807-815.

DOI:

$10.1641 / 0006-$ 3568(2001)051[0807:MFOOTW]2.0.CO;2

Warton, D. and F.K.C. Hui, 2011. The arcsine is asinine: The analysis of proportions in ecology. Ecology, 92: 3-10. DOI: 10.1890/10-0340.1 